\title{
SYNTHESIS OF AKAGANEITE IN THE PRESENCE OF SULFATE: IMPLICATIONS FOR AKAGANEITE FORMATION IN YELLOWKNIFE BAY, GALE CRATER, MARS
}

T. S. Peretyazhko', A. Fox ${ }^{2}$, B. Sutter', P. B. Niles ${ }^{3}$, M. Adams ${ }^{4}$, R.V. Morris ${ }^{3}$, D.W. Ming ${ }^{3} .{ }^{1}$ Jacobs, NASA Johnson Space Center, Houston, TX 77058 (tanya.peretyazhko@nasa.gov), ${ }^{2}$ Indiana University, Bloomington, IN 47406, ${ }^{3}$ NASA Johnson Space Center, Houston, TX 77058, ${ }^{4}$ University of Hawaii at Hilo, Hilo, HI 96720

Introduction: Akaganeite $(\beta-\mathrm{FeOOH})$ is an $\mathrm{Fe}(\mathrm{III})$ (hydr)oxide with a tunnel structure usually occupied by chloride. Akaganeite has been recently discovered in a mudstone on the surface of Mars by the Chemistry and Mineralogy (CheMin) and Sample Analysis at Mars (SAM) instruments onboard the Mars Science Laboratory (MSL) Curiosity Rover in Gale crater $[1,2]$. Akaganeite was detected together with sulfate minerals [anhydrite $\left(\mathrm{CaSO}_{4}\right)$ and basanite $\left.\left(2 \mathrm{CaSO}_{4} \cdot 2 \mathrm{H}_{2} \mathrm{O}\right)\right]$ in the drilled Cumberland and John Clein mudstone samples at Yellowknife Bay [2]. Discovery of akaganeite and sulfates in the same samples suggests that sulfate ions could be present in aqueous solution during akaganeite formation. However, mechanism and aqueous environmental conditions of akaganeite formation (e.g., $\mathrm{pH}$ and range of sulfate concentration) in Yellowknife Bay remain unknown.

The objective of our work was to perform synthesis of akaganeite without or with sulfate addition at variable $\mathrm{pHs}$ in order to constrain formation conditions of akaganeite in Yellowknife Bay, Gale crater on Mars.

Materials and Methods: Synthesis were performed through hydrolysis of $0.2 \mathrm{M} \mathrm{FeCl}_{3}$ solution with addition of $0,0.01,0.05,0.1$ and $0.2 \mathrm{M}$ sulfate. Iron(III) hydrolysis were run at initial $\mathrm{pH}$ of 1.5, 2 and 4 at $90{ }^{\circ} \mathrm{C}$ for $5 \mathrm{~h}$. The precipitates were then washed $3 \mathrm{x}$ with Milli-Q water by centrifugation and dried in the $70{ }^{\circ} \mathrm{C}$ oven overnight prior to mineralogy and composition characterization.

For total sulfate $(\mathrm{S})$ and chloride $(\mathrm{Cl})$ analysis, the dried precipitates were digested in $2.5 \mathrm{M} \mathrm{HNO}_{3}$. Total $\mathrm{S}$ was determined by Inductively Coupled Plasma Mass Spectrometry and total $\mathrm{Cl}$ by Ion Chromatography. Mineralogy of the precipitated $\mathrm{Fe}(\mathrm{III})$ phases was characterized using X-ray Diffraction (XRD) and Infrared Spectroscopy.

Results and Discussion: Solution $\mathrm{pH}$ decreased in all samples after $5 \mathrm{~h}$ heating at $90{ }^{\circ} \mathrm{C}$ due to $\mathrm{Fe}(\mathrm{III})$ hydrolysis and precipitation of $\mathrm{Fe}$ (III) phases. Mineralogical analysis by XRD revealed precipitation of diverse $\mathrm{Fe}(\mathrm{III})$ (hydr)oxides and natrojarosite at variable initial $\mathrm{S}$ concentration and $\mathrm{pH}$. Samples prepared at initial $\mathrm{pH}$ 1.5 with additions of $0,0.01$, and $0.05 \mathrm{M} \mathrm{S}$ containied pure akaganeite, mixture of natrojarosite and akaganeite with the addition of $0.1 \mathrm{M} \mathrm{S}$ and natrojarosite
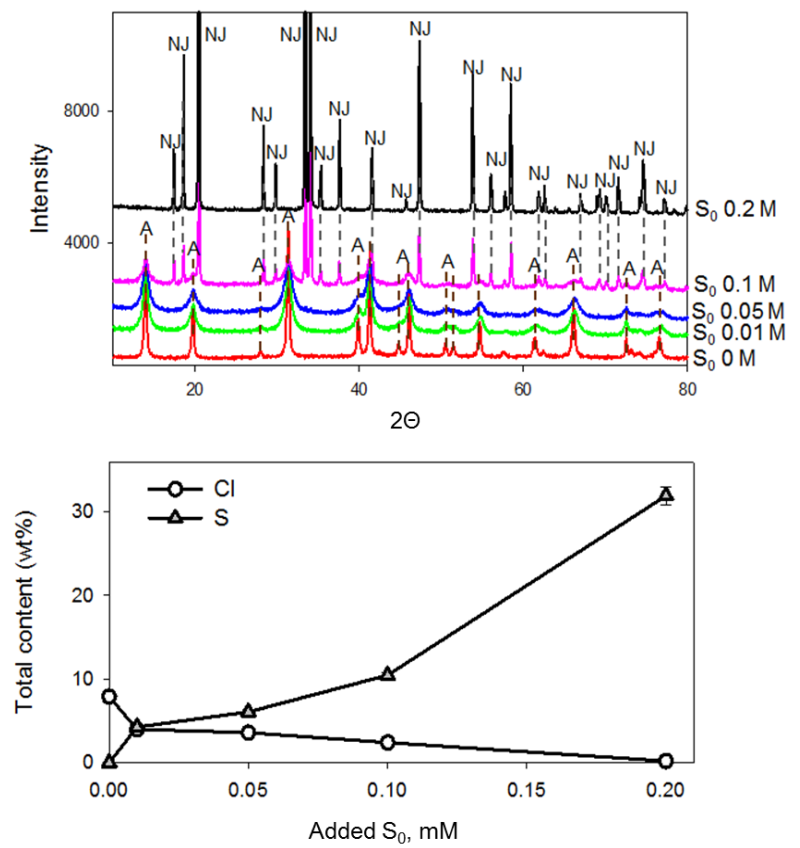

c

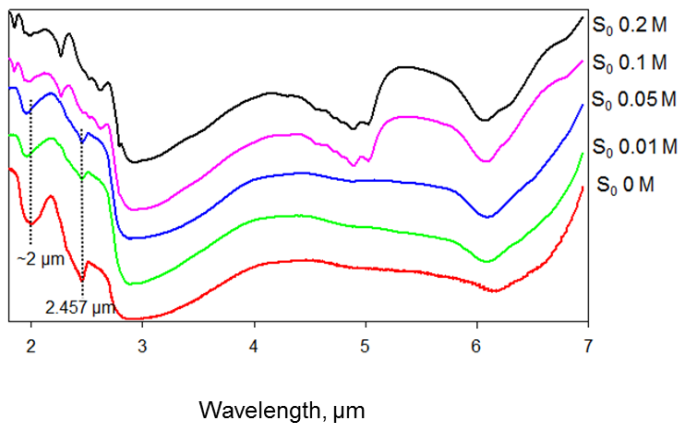

Fig. 1 (a) X-ray diffraction pattern of Fe(III) precipitates formed in the presence of different initial $S\left(S_{0}\right)$ concentration at initial pH $1.5(A=$ akaganeite, $N J=$ natrojarosite). (b) Total content of $\mathrm{Cl}$ and $\mathrm{S}$ in acid digested $\mathrm{Fe}(\mathrm{III})$ precipitates as a function of initial $S$ concentration at initial pH 1.5. (c) Continuum removed infrared spectra from 1.7 to $7 \mu \mathrm{m}$ of $\mathrm{Fe}(\mathrm{III})$ precipitates formed in the presence of different initial $S$ concentration at initial $p H$ 1.5. Diagnostic akaganeite combination bands at $\sim 2 \mu \mathrm{m}$ and $\sim 2.46 \mu \mathrm{m}$ are shown with the dotted lines. 
alone with additions of 0.2 M S (Figure 1a). Samples prepared at initial $\mathrm{pH} 2$ with no $\mathrm{S}$ addition contained akaganeite alone, mixture of akaganeite and goethite with addition of $0.01 \mathrm{M} \mathrm{S}$ and mixture of akaganeite, goethite and natrojarosite with additions of $0.05,0.1$ and 0.2 M S. Precipitation of akaganeite did not occur in any samples prepared at initial pH 4. Instead, 2-line ferrihydrite, hematite and goethite were precipitated.

Pure akaganeite formed without $\mathrm{S}$ addition contained the largest amount of total $\mathrm{Cl}$ (Figure 1b). Addition of the increasing $\mathrm{S}$ amount to the initial solutions led to total $\mathrm{S}$ increase and $\mathrm{Cl}$ decrease in the forming $\mathrm{Fe}$ (III) precipitates at all initial pHs (Figure 1b). Composition analysis also revealed that total $\mathrm{Cl}$ detected in mixtures in akaganeite-containing samples was associated with akaganeite tunnels.

Infrared spectroscopy revealed diagnostic akaganeite bands in the near-infrared range $\left(\mathrm{H}_{2} \mathrm{O}\right.$ combination band at $\sim 2 \mu \mathrm{m}$ and $\mathrm{OH}$ combination band at $\sim 2.46$ $\mu \mathrm{m}$, Figure 1c) which were previously used to identify akaganeite on Mars from orbital spectrometers [3]. The akaganeite bands at $\sim 2$ and $\sim 2.46 \mu \mathrm{m}$ presumably depended on the composition and $\mathrm{pH}$ of initial solutions from which akaganeite formed. The $\mathrm{H}_{2} \mathrm{O}$ combination band position linearly correlated with total $\mathrm{Cl}$ content in akaganeite. The $\mathrm{OH}$ combination band position varied between akaganeites synthesized at initial $\mathrm{pH} 1.5$ $(2.457 \mu \mathrm{m})$ and $\mathrm{pH} 2(2.463 \mu \mathrm{m})$. Both band positions might be therefore used to characterize past aqueous environmental conditions in deposits where akaganeite occurs on Mars.

Conclusions: Results of laboratory experiments demonstrated that akaganeite was synthesized through $\mathrm{Fe}(\mathrm{III})$ hydrolysis at initial $\mathrm{S}$ concentration $\leq 0.2 \mathrm{M}$ and initial $\mathrm{pH} \leq 2$ at $90^{\circ} \mathrm{C}$.

Akaganeite of nearly 2 wt\% was detected by CheMin XRD instrument in the drilled Cumberland mudstone in Yellowknife Bay on Mars along with 1 wt $\%$ pyrrhotite, $4.4 \mathrm{wt} \%$ magnetite and $0.7 \mathrm{wt} \%$ hematite [2]. Cumberland drill fines contained about 2.6 wt $\%$ sulfur and $1.4 \mathrm{wt} \%$ chlorine [4]. The presence of both elements could be favorable for akaganeite formation through solution precipitation under acidic conditions as shown in our laboratory study.

We propose that Yellowknife Bay experienced early acidic (probably localized) geochemical conditions favorable for akaganeite formation. One of the possible sources of localized acidity might be dissolution of $\mathrm{Fe}$ (II) sulfides such as pyrrhotite and pyrite. Akaganeite might precipitate through chemical oxidation of dissolved $\mathrm{Fe}$ (II) followed by $\mathrm{Fe}(\mathrm{III})$ hydrolysis in Cl-containing solution under hydrothermal conditions. Overall neutral conditions at Yellowknife Bay would make akaganeite unstable and it could partially transform to hematite [5] and magnetite [6]; both which have been detected in the Yellowknife Bay mudstone [2].

References: [1] Ming et al. (2014) Science, 343. [2] Vaniman et al (2014) Science, 343.[3] Carter et al. (2015) Icarus 253, 296-310, [4] McLennan et al. (2014) Science, 343. [5] Cornell and Giovanoli (1990) Clays Clay Miner. 38, 469-476. [6] Ishikawa et al. (1998) Corros. Sci. 40, 1239-1251. 